\title{
Forgotten Children of Sri Lanka
}

\author{
Pushpa M G Punchihewa ${ }^{1}$
}

Sri Lanka Journal of Child Health, 2006; 35: 47-50

(Key words: deprived children, Sri Lanka)

The UN Convention on the Rights of the Child (1989), for which Sri Lanka is a signatory, makes it mandatory for us to provide comprehensive care to all children below 18 years. The UN child right perspective emphasizes 4 basic rights:

- The right to survival, life, health, nutrition and adequate standard of living.

- The right to protection and freedom from exploitation, abuse, neglect and armed conflict.

- The right to development, education, early child care and security.

- The right to participation, freedom of expression and religion

Article 6 states that every child has the inherent right to life, and each country should ensure the child's survival and development to the maximum extent possible. But the implementation of the act is slow and expensive.

Most children today grow up loved and supported. However a significant number of children in Sri Lanka live in circumstances which are so dismal that one wonders how they survive with hope for any quality of future life. These children miss love, protection and warmth of parental care. They lack supervision and are devoid of best possible education. By losing these legitimate rights they undergo physical and mental stress. They miss the opportunities to grow to the best of their potential and place their survival, protection and development at significant risk. The future of these children will be damaged unless effective interventions are mounted.

I have identified the following as deprived children.

${ }^{1}$ Consultant Paediatrician, Teaching Hospital,
Karapitiya.

*Address given on induction as President SLCP, November 2005.

1. Culturally \& socio-economically deprived children.

2. Children in care.

3. Physically challenged children.

4. Infants \& children in prison.

Those children growing up in the midst of the war, who have an even more dismal future, are not discussed in this presentation.

\section{Culturally and socio-economically deprived children}

- Children living in poverty.

- Children in remote rural villages.

- Children of estate workers.

- Street children.

According to Department of Census and Statistics of Sri Lanka of 2004, 22.7\% of the population, in 7 provinces studied, live below the poverty line which is Rs.1,526 per month. (North and East have not been studied). $25 \%$ of the rural population live in poverty and $30 \%$ of the estate population are poor when compared with $8 \%$ of the urban population.

For children living in remote rural areas and for children from estate sector, poverty can be particularly devastating. Access to basic services is extremely difficult including public transportation. Rural children and estate children do not receive adequate health care as the facilities and health professionals are inadequate. Child and youth development opportunities are also limited. Education provided is often inadequate and substandard. Often they do not attend school as they have to assist their parents and at times look after younger children. According to Census of Population and Housing of 2004, remote rural and estate youth have a lower literacy rate. Poor performance at GCE $\mathrm{O} / \mathrm{L}$ exam further proves the existing discrepancy. 
Culturally \& socio-economically deprived children have a higher rate of malnutrition, child morbidity and child mortality. Demographic and health surveys of 2002 demonstrate that nutritional status of children is very poor in both rural and estate sectors. Percentages of stunted and underweight children are higher in estate sector when compared to rural sector. Infant mortality rate, which has a close relationship with mother's educational attainment, age of mother, birth order and birth interval, too, is highest in the estate sector.

Poverty is associated with psychosocial problems such as child labour, neglect, truanting, school failure, crime and out of wedlock teenage pregnancies. Behaviour and conduct disorders are also common problems seen in these children. Department of Census and Statistics demonstrated that $95 \%$ of the working children are from rural $\&$ estate sectors.

Family factors linked to the socially disadvantaged include alcohol abuse, substance abuse, cigarette smoking, family violence and separation. Unemployment and low income are associated with child maltreatment especially physical abuse and neglect. Marital stress is increased by the stress of relentless poverty. Maternal separation, as a result of foreign employment, traumatizes the children further. Exacerbating the above are homelessness and unemployment. Intergenerational cycle of poverty leads to maternal malnutrition that, along with poor antenatal care, lead to low birth weight babies perpetuating the risk of illness through adulthood.

Life style of street children exposes them to a greater than average risk of health problems. They are prone to more infections, accidents, sexually transmitted diseases, injuries caused by violence and substance abuse. They are also vulnerable to exploitation for criminal activities and often come into conflict with police.

Regardless of where they live, life is extremely hard for children growing up in poverty. Opportunities to grow and thrive are limited. The resulting damage can leave a deep scar on children decreasing their chances of succeeding in school, getting good jobs and leading a healthy life. These children in poor communities have little real chance of breaking free from the cycle of poverty, changing the circumstances of their lives and following their dreams. They also have very little hope of providing a different world for their own children who will grow up to be prisoners of the same poverty.

\section{Children in care}

There is a dual system of care, one run by the state and another run by non governmental organizations (NGOs). The total number of children in care, as at first November 2005, is 12,964. 1,933 are in state owned institutions while 11,034 are in the care of NGOs. Information provided here is only on state owned institutions:

- Detention home. There is only one centre for the whole of Sri Lanka. The children who are thrown away; have run away, street children, children sexually and physically abused, child domestic servants and children after minor offences are kept in this institution and 165 children between 5-18 years for both sexes were there at the time of my visit.

- Certified schools for juvenile offenders. Children are generally kept for 3 years.

- $\quad$ Remand homes for children. They are kept for a period of 2 weeks till the legal judgment is made.

- $\quad$ Receiving homes for children less than 5 years.

- “Senehasa” for sexually abused girls.

These children who are in care are likely to be poor and socially excluded even after they leave. They all need stability and support. Some need extra help. The system responsible is often not better than the homes from which they were taken. They are the responsibility of the State which itself should model 'good parenting'. The following key problems were identified:

- Residential facilities are of lower standard.

- $\quad$ Potentially dangerous children are kept with others.

- Children with special needs are not adequately served.

- Educational needs are not addressed fully. Those who have never schooled receive only a limited exposure to vocational training.

- It is often difficult to obtain complete health records and there are no regular visits by medical officers and other health workers. There is often diffusion of responsibility regarding obtaining health care services resulting in delay or denial of health services. 
- No good plan for preparing them for adulthood.

- No counselling facilities available leading to poorer psychological outcome with self harm and suicide.

- Transported and kept with other prisoners during legal procedures and thus at a risk of sexual abuse.

- Staff are inadequate and they are untrained.

- Funds and resources are inadequate.

- No regular monitoring, inspection and evaluation.

- No multidisciplinary team care.

\section{Physically challenged children}

According to Article 23 of UN convention, "a disabled child also has a right to special care, education, training and other privileges enjoyed by others". Based on Disability Census of 2001 there are approximately 285,632 disabled persons in Sri Lanka and $16 \%$ of them are children .Certain areas of northern \& eastern provinces have not been enumerated completely.

There is increasing concern about disparities and how the benefits reach these children. Even the basic support is often unavailable, inadequate and incomplete. Approach by under-trained therapists does not provide benefit and often does harm.

There are only very few centres which provide comprehensive care. Even when they are available these children have to be carried a long distance for therapy There is no proper inclusive education. The vast majority have never gone to school. Unimplemented policies, negative attitudes and shortage of information isolate them in the community. The physical environment excludes them in this country as there are no alternative facilities in public places. Public transport system is not suitable for the physically challenged. Employment opportunities are very scarce as there is no proper training for a suitable vocation.

\section{Infants and children in prison who are kept with imprisoned mother}

These children serve a sentence for crimes they never committed, condemned to this life as the unfortunate victims of their mother's crimes. It is also possible that a child could be separated from its imprisoned mother. This could be in direct contravention of the child's right to family life. There are minimum opportunities and no community experiences. Health care facilities are highly inadequate. Family visits and contacts are restricted.

\section{Solutions}

- Central Government must create laws, policies and give a strategic lead.

- Provincial councils must take responsibilities with the same seriousness.

- A public commitment is vital to show that policy makers are serious about transforming the life chances of these children.

- Monitoring and evaluation systems are mandatory.

- All children's services should combine to promote cross-departmental discussions on integrating education, social services and health services. This would give a unique opportunity to develop a longterm vision for these children, something that is sadly lacking.

\section{Conclusions}

- The welfare of children must always be regarded as of primary importance as their age and vulnerability renders them powerless to protect their own interests.

- The College of Paediatricians has a professional responsibility to protect these children.

- To claim that the society is one of equal opportunities, comprehensive service specifications should be drawn up by purchases in conjunction with providers and other relevant agencies such as social services, health, education, probation and child care and NGOs who care for children. 